\title{
Brevibacterium epidermidis
}

National Cancer Institute

\section{Source}

National Cancer Institute. Brevibacterium epidermidis. NCI Thesaurus. Code C86211.

A species of aerobic, Gram-positive, rod shaped bacteria assigned to the phylum Actinobacteria. This species is nonmotile, non-spore forming, catalase positive, oxidase negative, reduces nitrate and hydrolyzes gelatin and casein. B. epidermidis is a commensal part of human skin, but can be pathogenic in other locations. 